\title{
Elusive claims data hold promise for healthcare research
}

As the US government reworks the country's healthcare delivery system, information relating to insurance claims is quickly becoming a hot commodity.

In January, the US Department of Health and Human Services (HHS) announced a plan to construct a nationwide database of public and private insurance claims data for use in healthcare research. The Federal Coordinating Council for Comparative Effectiveness Research (CER) will use stimulus funding to construct the database for CER, a type of research popular with healthcare reform proponents that analyzes the benefits, risks and/or costs of various medical procedures to determine the best treatment for a given condition.

The HHS has already begun soliciting vendors to design the database, but implementation is unlikely to begin until September, says Patrick Conway, executive director of the Federal Coordinating Council. It remains unknown who will have access to the database or how the HHS will obtain private claims data. "It depends on the design and the access interface [of the database]," Conway told Nature Medicine.

The American Medical Association (AMA) is in favor of the database as a research tool, as long as research is not connected to physician payments or benefits, says Jeremy Lazarus, speaker for the AMA House of Delegates, the organization's policy-making body. "Physicians have a right to privacy," he says.

The HHS database may someday offer researchers better access to claims data, but private companies continue to struggle to access the information themselves. In December, a US federal appeals court ruled against a company seeking to obtain Medicare claims data-including doctors' names, addresses and performed proceduresvia the Freedom of Information Act. A unanimous three-judge panel ruled that the Department of Health and Human Services is not obligated to release the data to Real Time Medical Data, a private company that would sell it to hospitals, physicians and other medical entities.

In their decision, the judges cited a 1979 injunctive order barring disclosure of Medicare reimbursement amounts. The judgment is similar to a case argued last year in which a Washington, DC court of appeals prevented Consumers' Checkbook, part of the Center for the Study of Services, a nonprofit consumer information company, from obtaining Medicare data from the
HHS. The court ruled that disclosure of the data would result in a "clearly unwarranted invasion of personal privacy," adding that the information was not useful to patients, anyway.

Checkbook planned to use the data to create a free online site where patients could evaluate physicians on the basis of the number of procedures they had performed. "It is a very large data resource that would help the public, health plans, state healthcare agencies and consumers evaluate physician performance," says Robert Krughoff, Checkbook's president. Checkbook and
Real Time aren't the only parties interested in Medicare claims data: during Checkbook's appeal, the AARP and the Consumers Union of United States, among others, supported the company's request for data.

The rationale behind the two rulings was different, but the message is clear-Medicare claims data is off limits, even from the Freedom of Information Act. Checkbook has asked the US Supreme Court to review their case. "One way or another, it is very important that this data get out there," says Krughoff.

Megan Scudellari, Durham, North Carolina

\section{Troubles beset Thai health ministry}

In a reshuffling of Thailand's

government cabinet, the country's education minister, Jurin Laksanawisit, switched to take the position of public health minister and was confirmed in this new role on 18 January. The change comes after allegations that the previous leadership of the health ministry mismanaged a health spending program worth 86 billion baht ( $\$ 2.6$ billion) established as part of the Thai economic stimulus package.

The cabinet reshuffle was triggered by the resignations of former Public Health Minister Witthaya Kaewparadai and Deputy Minister Manit Nopamornbodee after an investigation prompted by allegations of irregularities raised in October by Thailandís Rural Doctors Society.

The Bangkok Post reported in October that the society's president, Kriangsak Vacharanukulkiat, had met personally with Thailand's prime minister Abhisit Vejjajiva to discuss the allegations.

Major concerns were raised about plans to purchase medical equipment that would have accounted for more than $25 \%$ of the procurement program. The ministry had reportedly planned to buy 80 ultraviolet sanitizers, 17 central monitors and 829 ambulances at prices that the society said were inflated.

The Rural Doctors Society slammed plans to purchase 13 anesthetic gas vaporizers for a total of 39 million baht because they were not appropriate investments for small district hospitals.

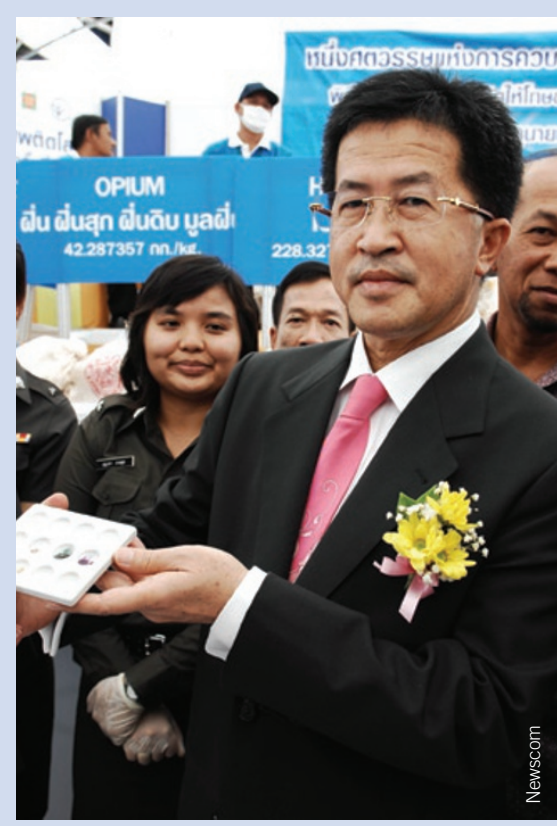

Lost in the shuffle: Outgoing health minister Kaewparadai

It also said the proposed purchase of 38 chemistry analyzers and 16 blood count machines was unnecessary, because these machines are available free of charge from manufacturers who gain revenue from sale of the chemicals required for their operation.

Kaewparadai reportedly denied that he approved the purchases and said they had not proceeded; similarly, Nopamornbodee said he was not involved in any irregular purchases. Simon Grose, Canberra, Australia 